\title{
SQI: Development index and application for two contrasting mediterranean landscapes
}

Jose Antonio Sillero-Medina, Paloma Hueso-Gonzalez, and Jose Damián Ruiz-Sinoga Málaga, Geomorphology and Soil, Geography, Málaga, Spain

Soil quality indexes (SQIs) are very useful in assessing the status and edaphic health of soils. This is particularly the case in the Mediterranean area, where successive torrential rainfall episodes give rise to erosion and soil degradation processes; these are being exacerbated by the current climate crisis. The objective of this study was to analyze the soil quality in two contrasting Mediterranean watersheds in the province of Malaga (Spain): the middle and upper watersheds of the Rio Grande (sub-humid conditions) and the Benamargosa River (semi-arid conditions). Field soil sampling was carried out at representative sites, and the soils were subsequently analyzed for various edaphic properties in the laboratory. From the resulting data, the mean values have been grouped and reclassified, and based on a multicriteria evaluation, a SQI for the study region was generated. The results show that there are major differences between the two watersheds, with optimal soil quality values being found in the Rio Grande watershed, but more unfavorable values occurring throughout most of the Benamargosa River watershed. 